\title{
LA EDUCACIÓN PARA LA PAZ: UNA ASIGNATURA PENDIENTE. LAS APORTACIONES DE BENEDICTO XVI
}

\author{
Antonio Alonso ${ }^{1}$ \\ UNISCI / Universidad CEU San Pablo \\ Carlos Corral $^{2}$ \\ UNISCI / Universidad Complutense de Madrid (UCM)
}

\begin{abstract}
Resumen:
El mensaje de Benedicto XVI para la XLV Jornada Mundial de la Paz, titulado "Educar a los jóvenes en la justicia y la paz", ha puesto sobre la mesa la pregunta de si es posible evitar las guerras y cuáles serían los instrumentos más eficaces para ello. Uno de los principales pilares que ayudan a sostener la estabilidad del sistema internacional es la educación, entendida, por un lado, como un proceso por el cual se van adquiriendo conocimientos y destrezas para el desempeño de las funciones propias en el mercado laboral, y también, por otro lado, como un proceso de asimilación, por parte de las nuevas generaciones, de unos valores y de unos criterios que les ayuden a la construcción de un orden social más justo y, por ende, más estable.
\end{abstract}

Palabras clave: Educación, paz, justicia, verdad, libertad, valores, Benedicto XVI.

Title in English: "Peace Education: A Failed Subject. Contributions from Benedict XVI”.

\begin{abstract}
:
The speech of Benedict XVI for the 45th World Day of Peace, whose title is "Educating Young People in Justice and Peace", has put on the table the question about whether is possible to avoid wars and which should be the most efficient instruments to do that. One of the main pillars of the stability of the international system is the education, understood, on one hand, as a process through which it is possible to acquire knowledge and skills useful for the labor market, and, on the other, as a process of assimilation, by the new generations side, of such values and criteria in order to build a social order fairer and more stable.
\end{abstract}

Keywords: Education, Peace, Justice, Truth, Freedom, Values, Benedict XVI.

Copyright (C) UNISCI, 2012.

Las opiniones expresadas en estos artículos son propias de sus autores, y no reflejan necesariamente la opinión de UNISCI. The views expressed in these articles are those of the authors, and do not necessarily reflect the views of UNISCI.

\footnotetext{
${ }^{1}$ Antonio Alonso Marcos es profesor del Instituto de Humanidades "Ángel Ayala”, Universidad CEU-San Pablo, e investigador de UNISCI. Dirección: Instituto de Humanidades “Ángel Ayala”, Universidad CEU-San Pablo, Paseo Juan XXIII, 8, 28040, Madrid.

Madrid, España. E-mail: aalonso@,ceu.es.

${ }^{2}$ Carlos Corral Salvador es Catedrático Emérito de Fuerzas Religiosas en la Sociedad Internacional de la Universidad Complutense de Madrid, e Investigador Senior de UNISCI. Sus principales líneas de investigación son la libertad religiosa, el Derecho Eclesiástico del Estado, los fundamentalismos religiosos y los Concordatos de la Santa Sede. Dirección: C/ Universidad Comillas, 7, 28049 Madrid, España. E-mail: ccorral@,res.upcomillas.es.
} 


\section{Introducción}

Gaston Bouthoul ${ }^{3}$, Julien Freund ${ }^{4}$ y Hannah Arendt ${ }^{5}$, entre otros -después de su experiencia de vivir dos guerras mundiales prácticamente consecutivas y la constante amenaza nuclearplantearon la cuestión de si las guerras podían ser evitadas, de si la violencia es un fenómeno ajeno a la naturaleza del ser humano o un mero producto de las relaciones económicas y sociales de un determinado momento histórico.

El Mensaje para la XLV Jornada Mundial de la Paz, que se celebra en el Vaticano cada 1 de enero desde 1968, lleva este año por título "Educar a los jóvenes en la justicia y la paz" y ha vuelto a poner sobre el tapete esa acuciante cuestión. Cada año, los papas se han fijando en un aspecto que ayudara a construir la paz. En concreto, Benedicto XVI se ha fijado en la necesidad de vincular paz y verdad (2006), la centralidad de la persona humana (2007) y de la familia (2008), la lucha contra la pobreza (2009), el respeto al medioambiente (2010) y la libertad religiosa (2011). El Santo Padre maneja, de esta manera, un concepto de paz y seguridad mucho más amplio que el del silencio de las $\operatorname{armas}^{6}$, tal y como afirma en el Mensaje para 2012:

"La paz no es sólo ausencia de guerra y no se limita a asegurar el equilibrio de fuerzas adversas. La paz no puede alcanzarse en la tierra sin la salvaguardia de los bienes de las personas, la libre comunicación entre los seres humanos, el respeto de la dignidad de las personas y de los pueblos, la práctica asidua de la fraternidad $^{7}$. . La paz es fruto de la justicia y efecto de la caridad. Y es ante todo don de Dios. ${ }^{8}$

Pero la educación no es una cuestión prioritaria solo para la Santa Sede sino que, como sucede con gran parte de la Doctrina Social de la Iglesia, es un tema de preocupación para muchas otras personas e instituciones que pueden no compartir la fe de la Iglesia de Roma.

Uno de los principales pilares que ayudan a sostener la estabilidad del sistema internacional es la educación, entendida, por un lado, como un proceso por el cual se van adquiriendo conocimientos y destrezas para el desempeño de las funciones propias en el mercado laboral, y también, por otro lado, como un proceso de asimilación, por parte de las nuevas generaciones, de unos valores y de unos criterios que les ayuden a la construcción de un orden social más justo y, por ende, más estable.

\footnotetext{
${ }^{3}$ Sobre Bouthoul ver Molina, Jerónimo: "Gaston Bouthoul. En conmemoración de un pionero de la Polemología”, Reis, no. 119 (2007), pp. 117-128; ver también Suanzes, Franco y Javier, Francisco: “Gaston Bouthoul. La guerra como función social", en Alonso Baquer, Miguel (coord.): "Ideas sobre prevención de conflictos", Cuaderno de Estrategia, no 111 (Febrero 2001); por último, ver la tesis doctoral de Parente Rodríguez, Gonzalo (2003): Evolución crítica del espectro del conflicto durante la segunda mitad del siglo XX y sus consecuencias para el nuevo orden mundial, Madrid, UCM.

${ }^{4}$ Este discípulo de Bouthoul profundizó en sus enseñanzas: Freund, Julien (1995): Sociología del conflicto. Madrid, Ediciones Ejército.

${ }^{5}$ El espíritu casi existencialista se deja traslucir en la obra de Arendt, Hannah (2006): Sobre la violencia, $1^{\text {a }}$ reimpresión. Madrid, Alianza Ed.

${ }^{6}$ Ver Alonso Marcos, Antonio y Corral Salvador, Carlos: "El concepto de seguridad humana en Benedicto XVI. Panorama del mundo 2008: Mensaje para la Jornada Mundial de la Paz y Discurso al cuerpo diplomático", UNISCI Discussion Papers, $\mathrm{n}^{\circ} 19$ (Enero 2009), en http://www.ucm.es/BUCM/revistas/cps/16962206/articulos/UNIS0909130268A.PDF.

7 "Catecismo de la Iglesia Católica", no 2304.

8 "Mensaje para la XLV Jornada Mundial de la Paz" (2012), nº 5.
} 
A lo largo de este artículo se mostrará cómo diversos estudios e informes reafirman la necesidad de promover una auténtica educación en valores, haciendo especial hincapié en el aprecio por la paz. También se aportarán las experiencias en el campo de la prevención de conflictos y de la reconstrucción post-conflicto, tareas que en ocasiones se entrecruzan.

\section{Evolución de los conceptos de paz y seguridad en el s. XX}

La Paz de Westfalia (1648) consagró no sólo un modelo de ordenación jurídico-política de los territorios (los Estados), sino que además estableció un sistema de relaciones entre ellos. A partir de ese momento, no cupo otra forma de entender la seguridad sino en términos de relaciones de poder, dominio y contención entre potencias. En ese contexto, la seguridad estaba gestionada directamente por los Estados y sólo pocas cosas se les escapaban. Las guerras formaban parte de este escenario, de manera que cada cierto tiempo se producía una de carácter regional y, con mayor espacio entre ellas, otra de carácter más amplio ${ }^{9}$. Así, el instrumento más utilizado por las potencias europeas (y por las demás emergentes) fue precisamente el equilibrio de poder, descrito por Robert Jervis así:

More frequently, states are restrained only externally, by what others are doing, or by the anticipation of what others will do if they act against the others' interests. This pattern characterizes the balance of power. Under the balance of power, a number of restraints are evinced: no state gains dominance, wars do not become total, unconditional surrenders are rare, the territory of losing states is not divided up among the winners, and usually the loser is soon reintegrated into the system. ${ }^{10}$

Esto era debido a que, como señaló Kenneth Waltz, el estado de naturaleza entre Estados es precisamente el de una lucha de todos contra todos ${ }^{11}$.

Sin embargo, la Primera Guerra Mundial (1914-18) supuso un punto de inflexión y, aunque otros antes ya habían apuntado la necesidad de crear instituciones que estuvieran por encima de los Estados para dirimir sus diferencias ${ }^{12}$, esta idea sólo fue posible tras la denominada Gran Guerra y su consiguiente deseo de nunca más volver a pasar por una experiencia tan traumática como la que se acababa de vivir, sea en lo personal, en lo social, en lo económico o en el campo político.

Pero las buenas intenciones manifestadas en los Catorce Puntos del presidente estadounidense Thomas Woodrow Wilson (1918) y plasmadas en la formación en 1919 de la Sociedad de Naciones ( $\mathrm{SdN}$ ) duraron más bien poco y al espíritu revanchista de la Paz de Versalles le siguió una política de appeasement que, en parte, propició el avance impune de

\footnotetext{
${ }^{9}$ Gaston Bouthoul se encargó en diversas ocasiones de estudiar este fenómeno. Ver por ejemplo Bouthoul, Gaston (1971): El fenómeno guerra, Barcelona, Plaza y Janés.

${ }^{10}$ Ver Jervis, Robert: "From Balance to Concert: A Study of International Security Cooperation", World Politics, vol. 38, nº 1 (Octubre 1985), p. 59.

11 "Montesquieu, Adam Smith, and Kant made no easy assumptions about the rationality and goodness of man. Among men in nature and states in a world of states, they found not harmony and peace but hostility and war to be the natural condition". Ver Waltz, Kenneth N.: "Kant, Liberalism, and War", The American Political Science Review, vol. 56, nº 2 (Junio 1962), p. 331.

${ }^{12}$ Ver la Presentación de Antonio Truyol Serra a la obra de Kant, Inmanuel (2009): Sobre la paz perpetua, $3^{\mathrm{a}}$ reimpresión, Madrid, Alianza Ed. En ese estudio previo cita a los precursores de este pensamiento institucionalista, entre otros, Sully, Emeric Crucé, William Penn, el abate de Saint-Pierre y J. Bentham.
} 
Hitler por Europa ${ }^{13}$. Basta recordar cómo engañó al resto de mandatarios en la conferencia de Múnich (septiembre de 1938) y pudo anexionarse impunemente los Sudetes y Austria. Bouthoul denominaba, con cierto tono peyorativo, "el ilusionismo jurídico" a esta fe ciega en los pactos alcanzados, lo que no implicaba "que se haya de proscribir el uso de los tratados o de los pactos. Sería absurdo, a pesar de los millares de mentís que les ha infligido a práctica"14.

No obstante, en los años 20 y 30 se alzaron numerosas voces que preconizaban la necesidad de crear instituciones internacionales o incluso supranacionales que velaran por proteger la paz mundial, siguiendo los principios de la que inspiraron la $\mathrm{SdN}$ : cooperación internacional, arbitraje de los conflictos y la seguridad colectiva. De esta manera, la responsabilidad de la seguridad había pasado, al menos en teoría, que no en la práctica, de manos de los Estados a una organización internacional.

El estallido de la segunda Guerra Mundial (1939-45) pulverizó toda esperanza de paz en un mundo marcado por el ansia de poder ${ }^{15}$. No obstante, las potencias aliadas, vencedoras de la contienda, desearon retomar el espíritu de la SdN y crearon la Organización de Naciones Unidas, que entroncaba con aquel pensamiento idealista, con aquella concepción ciertamente optimista del sistema internacional pues presuponía la inclinación natural de los pueblos al diálogo y la cooperación para superar los obstáculos ${ }^{16}$. Dicho espíritu se vio de nuevo truncado $^{17}$ con el levantamiento de "un telón de acero", en expresión de W. Churchill ${ }^{18}$, que dividió el mundo en dos bloques antagónicos, el occidental y el soviético, expresiones ambos de dos maneras distintas de entender la vida, la economía, la política, la sociedad y el ser humano. Así se inicia la Guerra Fría, caracterizada, según Kenneth Waltz:

The striking characteristics of world politics since the war have been these: peace among the powerful; their occasional use of force against others; war at times within and among the weak; the failure of such force as has been used to lead to wider wars at higher levels of violence. If one measures time from the termination of wars, 1967 stands to 1945 as 1940 does to 1918 . Never in this century have so many years gone by without the great powers fighting a general war. Small wars have been numerous, but somehow violence has been controlled and limited.

\footnotetext{
${ }^{13}$ Ver Ripsman, Norrin M. y Levy, Jack S.: "Wishful Thinking or Buying Time? The Logic of British Appeasement in the 1930s", International Security, vol. 33, n 2 (Invierno 2008), pp. 148-181. Ver también Barros, Andrew; Imlay, Talbot C.; Resnick, Evan; Ripsman, Norrin M. y Levy, Jack S.: "Correspondence: Debating British Decisionmaking toward Nazi Germany in the 1930s", International Security, vol. 34, $\mathrm{n}^{\circ}$, (Verano 2009), pp. 173-198.

${ }^{14}$ Ver Bouthoul, op. cit., p. 19. Ver también Bouthoul, G. (1948): Huit mille traités de paix. París, Juillard.

15 "It is indeed a big step from Wilson's Fourteen Points to the Atlantic Charter, and it is another big step from the Atlantic Charter to Dumbarton Oaks. At the beginning of the journey we witness the heroic and futile attempt to transform the political scene according to the postulates of liberal rationality. At the end of the journey we are in the presence of a less heroic and, we are afraid, no less futile attempt to mold the political reality in the image of Machiavelli's thought”. Ver Morgenthau, Hans J.: “The Machiavellian Utopia”, Ethics, vol. 55, n 2 (Enero 1945), p. 145.

${ }^{16}$ Ver Mearsheimer, John J.: "The False Promise of International Institutions", International Security, vol. 19, $\mathrm{n}^{\circ}$ 3 (Invierno 1994/95), pp. 5-49. Ver también Keohane Robert O. y Martin, Lisa L.: "The Promise of Institutional Theory", International Security, vol. 20, no 1 (Verano 1995), pp. 39-51. Por último, Jervis, Robert: "Realism, Neoliberalism, and Cooperation: Understanding the Debate”, International Security, vol. 24, nº 1 (Verano 1999), pp. 42-63.

${ }^{17}$ Ver Morgenthau, Hans J.: “The Twilight of International Morality”, Ethics, vol. 58, no 2 (Enero 1948), pp. 7999. Ver también Kupchan, Charles A. y Trubowitz, Peter L.: “The Illusion of Liberal Internationalism's Revival", International Security, vol. 35, no 1 (Verano 2010), pp. 95-109.

18 "Desde Stettin, en el Báltico, a Trieste, en el Adriático, ha caído sobre el continente un telón de acero. Tras él se encuentran todas las capitales de los antiguos Estados de Europa central y oriental". Ver el Discurso de Churchill en la Universidad de Fulton (Misuri), 5 de marzo de 1946.
} 
Despite dreadful dangers, a relative peace has prevailed. How has peace been prolonged and what are the prospects of extending our blessing. ${ }^{19}$

Además, ese enfrentamiento entre bloques se vio recrudecido cuando la Unión Soviética acabó en 1949 con la ventaja que disfrutaba el bloque occidental de ser los poseedores exclusivos del arma atómica ${ }^{20}$.

Con las diversas oleadas de independencia y el consiguiente surgimiento de nuevos Estados, apareció un tercer bloque, el de los países no alineados, y diversos autores comenzaron a preguntarse sobre otras cuestiones relacionadas con la seguridad y la estabilidad que no están directamente conectadas con los equilibrios de poder entre superpotencias sino con las condiciones internas de aquellos regímenes ${ }^{21}$.

Se impulsaron en esta época los llamados "estudios sobre la paz"22.

La crisis energética de 1973 puso en el centro del debate de la seguridad una dimensión que, si bien había estado presente, en esos momentos se tornó extremadamente sensible o, por decirlo en lenguaje político, escaló puestos en la agenda de seguridad hasta convertirse en asunto prioritario. Además, aquella época nos ha dejado testimonios de situaciones que se han venido repitiendo cíclicamente a lo largo de estos años, sin restarle un ápice de actualidad: "Iran's repeated threats to close the Strait of Hormuz will probably come to naught, but the unexpected often happens in the Middle East with consequent impact on the world's economy "23. O, como dice más claramente en este fragmento:

Over five years since the world's first energy crisis and well into its second, "energy security" remains a widely discussed but little understood problem. Iran has accentuated the supposed lesson of the Arab oil embargo of 1973-self-reliance in national energy supply must replace dependence on imported oil. Careful analysis, however, of the meaning of energy security and its role in the range of broader security issues is still lacking. ${ }^{24}$

Aquel espíritu idealista, de pacto, de cooperación, se retomó de nuevo en la Conferencia de Helsinki (1975), que dio lugar al nacimiento de la CSCE. Precisamente, estos encuentros

\footnotetext{
${ }^{19}$ Ver Waltz, Kenneth N.: "The Politics of Peace”, International Studies Quarterly, vol. 11, n 3 (Septiembre 1967), p. 199.

${ }^{20}$ La Unión Soviética detonó en el campo de pruebas de Semipalatinsk (actual Kazajstán) su primera bomba nuclear.

21 "A democracy may be called stabilized when it is legitimate and normally efficient. A regime is legitimate if the vast majority of those it governs regard it as such. The less a constitution is challenged, the more legitimate it is. It is the disappearance or scarcity of revolutionaries that sanctions the legitimacy of a democratic (or, as I prefer to call it, constitutional-pluralistic) regime. As for efficiency, it lies in the stability of governments and the consistency of majorities. It does not exclude error (the diplomacy of English democracy was not superior to that of French democracy between the two wars), but it does exclude inability to choose. Democracy involves orderly competition among parties and candidates for office. It is efficient, in our sense of the word, when legal competition gives rise in actual fact to a majority, a government, a popular will, when the law of the majority brings forth an executive who is capable of acting and opponents who are resolved or resigned not to paralyse the action of their momentarily fortunate rivals". Ver Aron, Raymond: "The Situation of Democracy: Western Political Institutions in the Twentieth Century", Daedalus, vol. 90, n 2, Ethnic Groups in American Life (Primavera 1961), p. 351.

${ }^{22}$ Ver Röling, Bert V. A.: "El hombre y la paz”, El Correo de la UNESCO (Enero 1966), pp. 22 y ss.

${ }^{23}$ Ver Abelson, Philip H.: "Progress toward Energy Security”, Science, vol. 223, no 4632 (13 Enero 1984), p. 121.

${ }^{24}$ Ver David A., Deese: "Energy: Economics, Politics, and Security”, International Security, vol. 4, n 3 (Invierno 1979-1980), p. 140.
} 
internacionales, institucionalizados posteriormente en la OSCE, han impulsado la idea de que para evitar las guerras hay que recurrir al diálogo y a la creación de mediadas de confianza (siguiendo una concepción realista de la seguridad, es decir, que la seguridad recae en los Estados $)^{25}$. Pero también ha impulsado la conciencia de que la seguridad del Estado está supeditada a la seguridad de las personas y, a su vez, que estas, los ciudadanos, son agentes o de paz o fuente de conflicto, escapando así al control estricto de los Estados ${ }^{26}$.

Aunque diversos autores ya abogaban en los años 80 por la ampliación de la agenda de seguridad a otros temas distintos de los estrictamente militares ${ }^{27}$, fue la caída del sistema de bloques entre 1989-91 la que propició la búsqueda de un nuevo paradigma de seguridad y unas nuevas prioridades ${ }^{28}$ en las que centrarse. A ello se refirió Stephen Walt:

Military power is not the only source of national security, and military threats are not the only dangers that states face (though they are usually the most serious). As a result security studies also includes what is sometimes termed "statecraft"-arms control, diplomacy, crisis management, for example. These issues are clearly relevant to the main focus of the field, because they bear directly on the likelihood and character of war. Because nonmilitary phenomena can also threaten states and individuals, some writers have suggested broadening the concept of "security" to include topics such as poverty, AIDS, environmental hazards, drug abuse, and the like (Buzan, 1983; N. Brown, 1989). Such proposals remind us that nonmilitary issues deserve sustained attention from scholars and policymakers, and that military power does not guarantee well-being. But this prescription runs the risk of expanding "security studies" excessively; by this logic, issues such as pollution, disease, child abuse, or economic recessions could all be viewed as threats to "security." Defining the field in this way would destroy its intellectual coherence and make it more difficult to devise solutions to any of these important problems. $^{29}$

Y de ello no dejaron de dar su testimonio entre otros Krause y Williams:

Even neorealist scholars like Mearsheimer, Van Evera, and Posen have noted that important aspects of conflictual relationships include the creation and perpetuation of national myths (through education, for example), symbolic gestures (threatening or otherwise), and political rhetoric. Such factors are

\footnotetext{
${ }^{25}$ Ver Alonso, Antonio: “Armados para la guerra: Sobre el ciclo vital de los conflictos armados”, Diálogo Filosófico, no 79 (Enero-Abril 2011), pp. 45-60.

${ }^{26}$ Sobre los distintos debates inter-paradigmáticos, ver Sodupe, Kepa (2003): La teoría de las Relaciones Internacionales a comienzos del siglo XXI. Vitoria, UPV, pp. 29-50. Ver también Barbé, Esther (2003): Relaciones Internacionales, Tecnos, Madrid.

${ }^{27}$ Ver Ullman, Richard H.: "Redefining Security", International Security, vol. 8, no 1 (Verano de 1983), pp. 129153. Ver también Nye, Joseph S. y Lynn-Jones, Sean M.: "International Security Studies: A Report of a Conference on the State of the Field", International Security, vol. 12, no 4 (Primavera de 1988), pp. 5-27. Por último, Laborie Iglesias, Mario: "La evolución del concepto de seguridad", Instituto Español de Estudios Estratégicos, Documento Marco 05/2011 (Junio 2011).

${ }^{28}$ Parece más apropiado decir "nuevas prioridades" antes que "nuevas amenazas" pues, por ejemplo, las guerras incitadas por el nacionalismo exacerbado, como fueron las de los Balcanes en los años 90, ya se habían dado a lo largo de la historia. El terrorismo, incluso el terrorismo internacional, también existía ya mucho antes de los atentados del 11-S.

${ }^{29}$ Ver Walt, Stephen M.: “The Renaissance of Security Studies”, International Studies Quarterly, vol. 35, nº 2 (Junio 1991), p. 213.
} 
manipulable variables in only a loose and indirect sense, yet they are the stuff of security in contemporary world politics. ${ }^{30}$

Durante los años 90 el tema estrella de la investigación internacionalista fue el proceso de globalización y las diferencias norte-sur, mientras que los estudios de seguridad se centraron en los enfrentamientos entre Estados o incluso entre bloques dejaron paso a la preocupación por las guerras civiles, por los frozen conflicts $^{31}$ o por las amenazas provenientes de entes no estatales (tráficos ilícitos, terrorismo, grupos guerrilleros,...).

Precisamente en esa época, la ONU produce una gran cantidad de documentos sobre las lecciones aprendidas en las misiones de paz en los que se hace hincapié en la educación como una de las medidas más importantes de prevención de conflictos y de reconstrucción postconflicto, como se verá más adelante. Entre esos documentos se encuentran Una Agenda para la paz, del Secretario General Boutros Boutros Ghali ${ }^{32}$.

Aunque los atentados del 11-S supusieron el pistoletazo de salida de la puesta en práctica, de nuevo, de un concepto clásico de seguridad (centralidad del Estado y de la seguridad nacional, práctica impunidad de la potencia hegemónica en su acción exterior,...), la educación sigue siendo un elemento esencial para la consecución de la paz mundial.

Como se ve, el trayecto de los estudios (y de los paradigmas) de seguridad en el s. XX bien pueden entenderse como una dialéctica entre realismo e idealismo, siendo, no obstante el primero la corriente principal o mainstream de esta disciplina. Es cierto que tras la Segunda Guerra Mundial aparecieron otros enfoques teóricos que hicieron aportaciones valiosas al estudio de la seguridad (como el conductismo, el globalismo, etc), pero siempre, como ha quedado demostrado, la forma de entender la seguridad ha vuelto a su enfoque principal, aunque con matices y algún que otro cambio de importancia.

\section{Paz y seguridad en la Doctrina Social de la Iglesia (DSI) del s. XX}

\subsection{Su concepción de la vida social}

La cuestión de la paz y la seguridad en la Doctrina Social de la Iglesia (DSI) es ciertamente compleja, si bien ha mantenido una melodía de fondo a lo largo del turbulento s. XX. Estos elementos permanentes son los siguientes.

En primer lugar, es menester atender a la concepción antropológica de la Iglesia. Ésta entiende que el hombre es un ser integrado por cuerpo y alma (concediendo, pues, exacta importancia a ambas dimensiones de la persona), un ser abierto a la trascendencia (y que, por tanto, no limita su existencia a este mundo) y un ser social por naturaleza, siguiendo a Aristóteles y a su intérprete cristiano, santo Tomás de Aquino.

\footnotetext{
${ }^{30}$ Ver Krause, Keith y Williams, Michael C.: "Broadening the Agenda of Security Studies: Politics and Methods", Mershon International Studies Review, vol. 40, no 2 (Octubre 1996), p. 249.

${ }^{31}$ Con el término frozen conflicts se hace referencia a aquellos conflictos sin resolver que aún hoy son causa de inestabilidad en repúblicas de la antigua URSS ya que cuando ésta se desmembró dejó una serie de territorios de una mayoría étnica que no se correspondía con el Estado en el que se encuadraba: Transnistria en Moldavia, Abjasia, Abjaria y Osetia en Georgia, y Nagorno Karabaj entre Armenia y Azerbaiyán. La OSCE ha dedicado, con éxito limitado, algunos esfuerzos orientados a intentar resolver estas situaciones fuente de inestabilidad. Ver: Blank, Stephen: "Russia and the Black Sea's Frozen Conflicts in Strategic Perspective", Mediterranean Quarterly, vol. 19, no 3 (Verano 2008), pp. 23-54.

${ }^{32}$ Ver el Informe del Secretario General de la ONU Boutros Ghali, A/47/277 - S/24111, de 17 de junio de 1992 : An Agenda for Peace: Preventive diplomacy, peacemaking and peace-keeping.
} 
Con respecto a esta última cuestión, la Iglesia entiende que la sociedad no puede ser una mera masa, un conglomerado de números despersonalizados ${ }^{33}$, sino una auténtica comunidad en la que cada individuo participe activamente en la consecución del bien común. Este "bien común" puede ser definido de muchas maneras, pero se acepta, de manera general, que se refiere a un "conjunto de condiciones sociales que permitan a los ciudadanos el desarrollo expedito y pleno de su propia perfección"34.

Este bien común está siempre íntimamente ligado a una recta concepción de la persona humana y de su naturaleza. Precisamente, el principio iusnaturalista, esto es, la afirmación de que existe un orden natural previo al estado que debe ser respetado, es el que garantiza que se busque en sociedad lo que favorece al hombre y no lo que le destruye, por más que parezca en un determinado momento a una amplia mayoría de la población que las soluciones que se aportan son las más eficaces o la más útiles. Precisamente, el s. XX nos ha dado muestras más que suficientes de cómo el hombre, el poder político, cuando toma decisiones en contra del propio hombre, se convierte en un ser despiadado exterminador del prójimo inocente.

De aquí que los papas hayan defendido el valor tanto, por un lado, del sujeto rector de la sociedad, encargado de ostentar la autoridad, necesaria siempre para la construcción de toda sociedad, como, por otro lado, del sujeto regido de la sociedad, sin cuya participación, de manera individual o asociada, la sociedad carecería de uno de sus elementos más importantes y sería una simple masa manipulable al antojo del poder de turno.

En este punto, es preciso señalar que la Iglesia entiende por "autoridad" aquella facultad de mandar y ser obedecido, no como resultado de unos meros procedimientos formales sino como reflejo de Aquel que gobierna el universo. Para prevenir cualquier absolutismo arbitrario conviene recordar aquí la distinción que hizo san Anselmo de Canterbury (10331109) entre la potentia absoluta (poder absoluto) de Dios, que le permitió crear cualquier tipo de universo y la potentia ordinata (poder ordenado) por el que Él mismo se somete a las leyes impresas en el universo que ha creado. Se cierra así el círculo, señalando que la autoridad debe someterse en todo momento a la Ley Natural, ya que si se desliga de esta se autoderriba del pedestal moral que le legitima para ser obedecida y se convierte, por el contrario, en un mero poder fáctico coactivo, obedecido sólo por los instrumentos del miedo y la coacción. Por eso, la Iglesia ha defendido que la autoridad debe ser siempre obedecida, salvo que esta deje de respetar la Ley Natural y mande hacer cosas contrarias a esta.

Al respecto escribió con meridiana claridad el último papa aristócrata que, al menos hasta el momento ha tenido la Iglesia, Eugenio cardenal Pacelli, más conocido como Pío XII. Él, primero como nuncio en Baviera y luego como Secretario de Estado del Vaticano, pudo contemplar el ascenso de Hitler en Alemania por medios democráticos y cómo comenzó a poner en marcha una horripilante maquinaria de sometimiento de pueblos y persecución y exterminio del pueblo judío. Su predecesor, Pío XI, publicó una encíclica, el documento papal de mayor rango e importancia, condenando el régimen nazi titulado Mit Brenneder Sorge que, como se aprecia por el título, fue escrita originalmente en alemán, algo que jamás había sucedido en la Iglesia Católica pues se solía hacer en latín. Hoy pocos ponen en duda que dicha encíclica fuera redactada directamente por el cardenal Pacelli, tanto por su conocimiento del idioma como de la situación del país teutón.

\footnotetext{
${ }^{33}$ Tanto el pensamiento liberal como el socialismo defienden una idea de sociedad atomizada en la que las personas viven, en cada sistema de una manera distinta pero, al fin y al cabo esencialmente iguales, separadas unas de otras, desconectadas de la familia o la tradición, lazos que le unen a un proyecto común con rostro humano muy distinto del despersonalizado y des-personalizador Estado liberal o socialista.

${ }^{34}$ Aunque Pío XII ya se refiere a este bien común en su discurso Con sempre, en su apartado 13, esta definición tomada de la encíclica Mater et Magistra $\left(\mathrm{n}^{\circ}\right.$ 65) es la que después fue retomada en el Concilio Vaticano II (Gaudium et spes, 26 y 74).
} 
Siendo ya Pío XII y sorprendido por la Segunda Guerra Mundial, no cesó en hacer llamamientos constantes a la paz y la reconciliación y el establecimiento de un orden internacional justo. Testimonio de ello son, especialmente, su primera encíclica (Summi Pontificatus) y sus radiomensajes de Navidad del período bélico (1939-45). En ellos afirma la necesidad de que la autoridad sea siempre obedecida y de que esta se ciña a la Ley Natural, reivindicando un espacio para la libertad de la conciencia del gobernado.

Por último, se afirma la paz sólo se puede construir sobre la base de la justicia ${ }^{35}$, de la justicia social, es decir, del respeto escrupuloso a la construcción de orden social en el que se reconozca y se dé a cada uno lo suyo (unicuique suum tribuere, en expresión del Derecho Romano). El quid de la cuestión aquí es, precisamente, determinar ese "lo suyo", darle cuerpo, concretarlo, de manera que no se incurra en injusticia. Así, el Concilio Vaticano II desglosó en varios momentos qué entendió por sociedad justa. No es difícil entender que a tan sólo quince años de la proclamación de la Declaración Universal de los Derechos Humanos (1948), dicho concilio entró en sintonía con lo expresado en San Francisco.

\section{2. ¿ Qué es la paz?}

Sin pretender explicar por completo todo lo que dice la Iglesia sobre la paz, es necesario delimitar algunos conceptos básicos.

Los distintos mensajes para la Jornada Mundial de la Paz que se han venido celebrando sucesivamente desde el 1 de enero de 1968 han ido aportando un auténtico glosario y compendio de la doctrina de la Iglesia sobre la paz. En primer lugar, la Iglesia ha tomado como punto de referencia en numerosas ocasiones la definición de paz que dio san Agustín en su De civitate Dei (Libro 19, $\mathrm{n}^{\circ}$ 13): "pax omnium rerum tranquillitas ordinis", la tranquilidad de todas las cosas en el orden. No obstante, la paz no es sólo una cuestión exterior, sino un fruto del Espíritu Santo, por tanto don de Dios a quienes trabajan por el Bien. Además, como expresara Juan XXIII en su encíclica Pacem in terris, la paz está muy relacionada con otros cuatro elementos: la verdad, la justicia, el amor y la libertad ${ }^{36}$. Los papas han ido exponiendo cíclicamente temas relacionados con la consecución de una paz justa en el mundo. La educación para la paz, por ejemplo, fue el eje central de los mensajes de 1970, 1979 y 2004 y vuelve a serlo en $2012^{37}$.

Más aún, la Iglesia siempre ha manifestado su confianza en la capacidad de las instituciones internacionales, especialmente la ONU, para velar y trabajar por la paz. De ahí que en numerosas ocasiones haya hablado sobre la reforma de la dicha organización para que llegue a convertirse en un auténtico referente moral, en una verdadera autoridad mundial que pueda llegar a imponer la paz en todo el mundo. Los distintos tratados de paz firmados y posteriormente violados, la realidad de la guerra, presente siempre en la historia de la humanidad $^{38}$, llevan a la conclusión lógica de que dichos acuerdos internacionales son papel mojado y que muy probablemente la paz es una utopía que nunca se podrá conseguir. Sin embargo, la voz de la Iglesia ha sido muy clara a este respecto:

\footnotetext{
${ }^{35}$ La paz es fruto de la justicia. Así lo afirmó Juan Pablo II, hasta en tres ocasiones consecutivas, durante su Mensaje para la Jornada Mundial de la Paz del año 2004: "No hay paz sin justicia, no hay justicia sin perdón”.

${ }^{36}$ Ver Pacem in terris, $\mathrm{n}^{\mathrm{o}} 35$.

${ }^{37}$ Los títulos de dichos mensajes son Educarse para la paz a través de la reconciliación; Para lograr la paz, educar a la paz; Un compromiso siempre actual: educar a la paz; y por último Educar a los jóvenes en la justicia y la paz.

${ }^{38}$ Según Beer, tomando el símil de la salud y la enfermedad, paz y guerra van naturalmente alternándose a lo largo de la historia de la humanidad. Ver Beer, Francis A.: "The Epidemiology of Peace and War", International Studies Quarterly, vol. 23, no 1 (Marzo 1979), pp. 45-86.
} 
He aquí en cambio nuestro mensaje, el vuestro, hombres de buena voluntad, el mensaje de la humanidad universal: ¡la paz es posible! ¡debe ser posible! Sí, porque este es el mensaje que nos viene de los campos de las dos guerras mundiales y de otros conflictos armados recientes, que han ensangrentado la tierra; es la voz misteriosa y tremenda de los Caídos y de las víctimas de los conflictos pasados; es el gemido lastimoso de las innumerables tumbas de los cementerios militares y de los monumentos sagrados a los Soldados Desconocidos: la paz, la paz, no la guerra. La paz es la condición y la síntesis de la humana convivencia. ${ }^{39}$

Testimonio elocuente de la convicción profunda de los papas sobre la vinculación entre paz, justicia y reconciliación es la encíclica Pacem Dei munus, de Benedicto XV, publicada poco después del fin de la Primera Guerra Mundial:

Porque, si bien la guerra ha cesado de alguna manera en casi todos los pueblos y se han firmado algunos tratados de paz, subsisten, sin embargo, todavía las semillas del antiguo odio. Y, como sabéis muy bien, venerables hermanos, no hay paz estable, no hay tratados firmes, por muy laboriosas y prolongadas que hayan sido las negociaciones y por muy solemne que haya sido la promulgación de esa paz y de esos tratados, si al mismo tiempo no cesan el odio y la enemistad mediante una reconciliación basada en la mutua caridad. ${ }^{40}$

El Concilio Vaticano II volvió a tomar esta idea con un párrafo que parece evocar aquellas primeras palabras de la Paz Perpetua de Kant en la que habla de la paz de los cementerios:

Que no nos engañe una falsa esperanza. Pues, si no se establecen en el futuro tratados firmes y honestos sobre la paz universal una vez depuestos los odios y las enemistades, la humanidad, que ya está en grave peligro, aun a pesar de su ciencia admirable, quizá sea arrastrada funestamente a aquella hora en la que no habrá otra paz que la paz horrenda de la muerte. ${ }^{41}$

\subsection{Sobre la instauración de una autoridad mundial}

Una de las soluciones prácticas que el magisterio pontificio ha aportado desde comienzos del s. XX a la resolución de conflictos es el establecimiento de una autoridad mundial capaz de imponer la paz a todas las naciones. Esta propuesta tiene ciertas reminiscencias kantianas, quien propuso una república mundial (Weltrepublik) basada en una ciudadanía mundial (Weltbürgerrecht).

\footnotetext{
${ }^{39}$ Ver el Mensaje de Pablo VI para la celebración de la VI Jornada de la Paz, lunes 1 de enero de 1973, La paz es posible. De ahí que Juan Pablo II mostrara su extrañeza, llena más de pesar que de ingenuidad, ante el hecho de que "Las guerras, conflictos, actitudes racistas y xenófobas aún dominan demasiado el mundo de las relaciones humanas". Ver Juan Pablo II, Exhortación Apostólica Postsinodal Ecclesia in Africa, sobre la Iglesia en África y su misión evangelizadora hacia el año 2000, 14 de septiembre de $1995, \mathrm{n}^{\circ} 79$.

${ }^{40}$ Benedicto XV, Pacem Dei munus, 23 de mayo de 1920, $\mathrm{n}^{\circ} 1$. Semejante razonamiento es utilizado en el $\mathrm{n}^{\circ} 3$ : "No hacen falta muchos argumentos para demostrar los gravísimos daños que sobrevendrían a la humanidad si, firmada la paz, persistiesen latentes el odio y la enemistad en las relaciones internacionales".

${ }^{41}$ Ver Gaudium et spes, 82.
} 
Los sucesivos papas saludaron el surgimiento de un "nuevo ordenamiento internacional" 42 y hablaron de una sociedad de naciones, una auténtica "familia de pueblos" o una comunidad internacional que estaría regida por una autoridad de semejante ámbito. Así lo afirmaba Benedicto XV en 1920:

Restablecida así la situación, reconocido de nuevo el orden de la justicia y de la caridad y reconciliados los pueblos entre sí, es de desear, venerables hermanos, que todos los Estados olviden sus mutuos recelos y constituyan una sola sociedad o, mejor, una familia de pueblos, para garantizar la independencia de cada uno y conservar el orden en la sociedad humana. Son motivos para crear esta sociedad de pueblos, entre otros muchos que omitimos, la misma necesidad, universalmente reconocida, de suprimir o reducir al menos los enormes presupuestos militares, que resultan ya insoportables para los Estados, y acabar de esta manera para siempre con las desastrosas guerras modernas, o por lo menos alejar lo más remotamente posible el peligro de la guerra, y asegurar a todos los pueblos, dentro de sus justos límites, la independencia y la integridad de sus propios territorios. $^{43}$

La encíclica Pacem in terris da un paso más y, si bien lo que decía el concilio se podía entender hacia dentro de los Estados, el papa Juan XXIII fue muy explícito a la hora de señalar la existencia de un bien común universal, la paz, que debía ser preservado no sólo por un Estado o por un bloque de Estados sino por todos. En dicho documento afirmó la necesidad de una autoridad política mundial que luchara por la paz. Así lo expresa en su $n^{\circ}$ 136:

Ahora bien, si se examinan con atención, por una parte, el contenido intrínseco del bien común, $y$, por otra, la naturaleza y el ejercicio de la autoridad pública, todos habrán de reconocer que entre ambos existe una imprescindible conexión. Porque el orden moral, de la misma manera que exige una autoridad pública para promover el bien común en la sociedad civil, así también requiere que dicha autoridad pueda lograrlo efectivamente. De aquí nace que las instituciones civiles -en medio de las cuales la autoridad pública se desenvuelve, actúa y obtiene su fin- deben poseer una forma y eficacia tales que puedan alcanzar el bien común por las vías y los procedimientos más adecuados a las distintas situaciones de la realidad.

La tercera encíclica de Benedicto XVI, Caritas in veritate, habla en tres ocasiones sobre la necesidad de una autoridad mundial, no para que sustituya a los Estados sino para que ayude a regular el "mercado único" de una manera "más humana" ( $\left.{ }^{\circ} 41\right)$, para que luche por conseguir el bien común global ( $n^{\circ}$ 57), subrayando que "dicha autoridad deberá estar

\footnotetext{
42 "El nuevo orden internacional que se proponen instaurar los hombres de buena voluntad, ¿no supone que los menos favorecidos ocupen su puesto pleno y completo en la sociedad moderna y dejen ya de ser tratados como marginados?". Ver, el Mensaje de Juan Pablo II para la XVI Jornada Internacional de Alfabetización, 25 de agosto de 1982. Otro ejemplo lo tenemos en "La doctrina social de la Iglesia [...] ofrece orientaciones estimulantes para la promoción de los derechos humanos, para la tutela de la familia, para el desarrollo de instituciones políticas verdaderamente democráticas y participativas, para una economía al servicio del hombre, para un nuevo orden internacional que garantice al mismo tiempo la justicia y la paz entre los pueblos [...]", en el Mensaje de Juan Pablo II a los miembros de la fundación vaticana "Centesimus annus, pro Pontifice" en su décimo aniversario, 5 de julio de 2003. Por último, ver el Mensaje de Juan Pablo II para la XXXVII Jornada Mundial de la Paz (2004): Un compromiso siempre actual: educar a la paz, $\mathrm{n}^{\circ} 7$.

${ }^{43}$ Benedicto XV, Pacem Dei munus (23 Mayo 1920), nº 13.
} 
organizada de modo subsidiario y con división de poderes, tanto para no herir la libertad como para resultar concretamente eficaz". Por último, dicha "Autoridad política mundial" ( $\mathrm{n}^{\mathrm{o}}$ 67) deberá

estar regulada por el derecho, atenerse de manera concreta a los principios de subsidiaridad y de solidaridad, estar ordenada a la realización del bien común, comprometerse en la realización de un auténtico desarrollo humano integral inspirado en los valores de la caridad en la verdad. Dicha Autoridad, además, deberá estar reconocida por todos, gozar de poder efectivo para garantizar a cada uno la seguridad, el cumplimiento de la justicia y el respeto de los derechos. Obviamente, debe tener la facultad de hacer respetar sus propias decisiones a las diversas partes, así como las medidas de coordinación adoptadas en los diferentes foros internacionales.

Y concluye ese $n^{\circ} 67$ diciendo:

El desarrollo integral de los pueblos y la colaboración internacional exigen el establecimiento de un grado superior de ordenamiento internacional de tipo subsidiario para el gobierno de la globalización, que se lleve a cabo finalmente un orden social conforme al orden moral, así como esa relación entre esfera moral y social, entre política y mundo económico y civil, ya previsto en el Estatuto de las Naciones Unidas.

Aunque huelga decirlo, no han sido los papas los únicos que han constatado que ante la ausencia de una autoridad superior a la de los Estados estos se han dedicado a hacerse la guerra, como un elemento más de las civilizaciones ${ }^{44}$. Tal y como señaló, entre otros, Raymond Aron:

Within each of them, the rival ambitions of individuals or groups, ethnic heterogeneity, and opposition of interests created a permanent risk of illegitimate violence. Between societies, recourse to armed force was legitimate since, in the absence of civil authority, each could count only on itself to ward off all perils and to survive. ${ }^{45}$

Tampoco es exclusiva de la Iglesia Católica la conciencia de que sin reconciliación no hay paz posible:

[...] un apremiante llamamiento a la reconciliación, condición indispensable para instaurar en África relaciones de justicia entre los hombres y para construir una paz justa y duradera en el respeto de cada individuo y de cada pueblo; una paz que necesita y se abre a la aportación de todas las personas de buena voluntad más allá de sus respectivas pertenencias religiosas, étnicas, lingüísticas, culturales y sociales. ${ }^{46}$

\footnotetext{
44 "The conflicts between states, more or less regulated by tradition, custom, or laws, form an integral part of civilizations; they belong not to the biological order, but to the human order". Ver Aron, Raymond: "The Anarchical Order of Power", Daedalus, vol. 95, n 2, Conditions of World Order (Primavera 1966), p. 482. ${ }^{45}$ Ibid., pp. 483-484.

${ }^{46}$ Ver Concelebración eucarística para la clausura de la II Asamblea especial para África del sínodo de los obispos, homilía de Benedicto XVI, domingo 25 de octubre de 2009.
} 


\section{La educación para la paz}

Como se ha afirmado anteriormente, la educación ha sido un tema tratado reiteradamente por los pontífices ya que son conscientes de su importancia a la hora de construir, no solo desde arriba, desde el sujeto rector, sino también desde la base social, el sujeto regido, un mundo en paz. Es, además, el tema del Mensaje para la Jornada Mundial de la Paz de 2012.

\subsection{Antecedentes}

Hasta en tres ocasiones distintas, los papas han hablado de la educación para la paz antes de 2012. La primera ocasión fue en 1970, cuando Pablo VI puso de manifiesto que la paz, atendiendo a la definición agustiniana antes aludida de tranquillitas ordinis, es más bien un proyecto antes que un estado, un quehacer antes que un acto. Además, en ese proyecto deben involucrarse todos los hombres, pero, y aquí es donde se introduce la variable de la educación, las ideologías imperantes sofocan cualquier brote de paz ya que estas están alimentadas por el odio, el rencor y el egoísmo y ninguno de esos tres elementos conducen a la paz sino, más bien, al rebrote de la violencia. De ahí la necesidad de aprender "el evangelio del perdón" que, con su pedagogía, hace posible unas nuevas relaciones humanas entre vencedores y vencidos:

Una Paz, sin clemencia, ¿cómo puede llamarse tal? Paz saturada de espíritu de venganza, ¿cómo puede ser verdadera? De una parte y de otra es necesario el recurso a aquella justicia superior que es el perdón, el cual hace desaparecer las cuestiones insolubles de prestigio y hace todavía posible la amistad. ${ }^{47}$

Juan Pablo II tomó el testigo de su predecesor y dedicó su primer Mensaje para la Jornada Mundial de la Paz, el de 1979, a la cuestión de la educación. El Romano Pontífice aportó aquí una serie de claves para formar al espíritu humano, para educarle en la relectura de los acontecimientos históricos y ayudarle a superar la barrera de lo evidente, trascender lo obvio y salir al encuentro de la posibilidad de la paz:

una educación digna de este nombre es mirar más allá de las tristes evidencias inmediatas, o más bien, aprender a reconocer, en el meollo mismo de los estallidos de la violencia que mata, el camino discreto de la paz que jamás renuncia, que incansablemente cura la heridas, que mantiene y hace progresar la vida. $^{48}$

Propuso, además, hacer una relectura de la historia de la humanidad descubriendo que la fuerza que hace avanzar al hombre no es la violencia sino el deseo de progresar, de vivir en paz. Invita, además, a descubrir en el presente y difundir dichos esfuerzos: "Sí, sin ignorar el drama de las violencias, llenemos nuestras miradas y la de las jóvenes generaciones con estos objetivos de paz: son éstos los que ejercerán una atracción decisiva". Dentro aún del campo de la educación, pidió el papa cambiar el lenguaje, que habla de lo que está lleno el corazón, ya que éste, casi sin darnos cuenta, está repleto de esquemas de enfrentamiento. Pidió, por eso mismo, hacer gestos elocuentes de paz, exhortando así a padres y educadores:

\footnotetext{
${ }^{47}$ Ver el Mensaje de Pablo VI para la III Jornada Mundial de la Paz, 1 de enero de 1970, Educarse para la paz a través de la reconciliación, $\mathrm{n}^{\circ} 1$.

${ }^{48}$ Ver el Mensaje de Juan Pablo II para la XII Jornada Mundial de la Paz, 1 de enero de 1979, Para lograr la paz, educar a la paz.
} 
Padres y educadores, ayudad a los niños y a los jóvenes a hacer la experiencia de la paz en las mil acciones diarias que están a su alcance, en familia, en la escuela, en el juego, la camaradería, el trabajo en equipo, la competición deportiva, las múltiples conciliaciones y reconciliaciones necesarias. ${ }^{49}$

Por último, Juan Pablo II $^{50}$ volvió a tocar el tema de la educación en su mensaje de 2004. En él, parte de una premisa fundamental: "La Iglesia, en cambio, ha enseñado siempre y sigue enseñando una evidencia muy sencilla: la paz es posible. Más aún, la Iglesia no se cansa de repetir: la paz es necesaria" ${ }^{, 51}$. En esta pedagogía para alcanzar la paz es necesario, según el criterio del papa Wojtyla, enseñar a "respetar el orden internacionaly observar los compromisos asumidos por las Autoridades, que los representan legítimamente" ya que "la paz y el derecho internacional están íntimamente unidos entre sí: el derecho favorece la $p a z{ }^{, 52}$. No hay que olvidar que el año 2003 contempló el lento proceso de desplazamiento de tropas hacia el Golfo Pérsico y toda la concienzuda preparación para la guerra de Irak, que duró apenas un mes entre marzo y abril, y la cruda reconstrucción del país (tarea esta última que duró más de un mes, más de un año y, muy probablemente, más de una década). Hay que recordar, además, lo hondo que caló en el papa esta nueva intervención estadounidense en Irak y todas las gestiones diplomáticas y públicas que realizó para evitar dicho enfrentamiento. Juan Pablo II lanzó desde la ventana de sus apartamentos, en el rezo del ángelus del 16 de marzo de 2003, un bello discurso contra la aventura militar de Estados Unidos con su grito "mai più la guerra" (nunca más la guerra):

Yo pertenezco a la generación que vivió la segunda guerra mundial y sobrevivió. Siento el deber de decir a todos los jóvenes, a los más jóvenes que yo, que no tienen esa experiencia: "¡Nunca más la guerra!, como dijo Pablo VI en su primera visita a las Naciones Unidas. Debemos hacer todo lo posible. Sabemos muy bien que no es posible la paz a toda costa. Pero todos sabemos cuán grande es esta responsabilidad. Por tanto, ;oración y penitencia! $!^{53}$

Al finalizar el mensaje de 2004, el papa apuntó que a la justicia debía acompañarla el amor ya que aunque "El derecho es, ciertamente, el primer camino que se debe tomar para llegar a la paz. Y los pueblos deben ser formados en el respeto de este derecho. Pero no se llegará al final del camino si la justicia no se integra con el amor, ${ }^{\text {,54. }}$.

\subsection{Mensaje para la XLV Jornada Mundial de la Paz (2012)}

El destino del mensaje ha sido dirigido por papa principalmente a los jóvenes, como una reverberación de la Jornada Mundial de la Juventud celebrada en Madrid en agosto de 2011. $\mathrm{Y}$ así se pone de manifiesto en distintos momentos del Mensaje, especialmente en la parte final, que es una especie de exhortación a los jóvenes para que busquen lo más auténtico y trabajen por construir un mundo en paz. Pero, además, todo el discurso está cargado de un

\footnotetext{
${ }^{49}$ Ibid., $\mathrm{n}^{\mathrm{o}} 3$.

${ }^{50}$ Desde el primer momento de su pontificado, la preocupación por la paz estuvo presente. La primera prueba de fuego, manifestada ya por los cardenales tras el cónclave en el que salió elegido papa, fue el enfrentamiento entre Chile y Argentina por el Estrecho de Beagle, donde intervino como mediador.

${ }^{51}$ Ver el Mensaje de Juan Pablo II para la XXXVII Jornada Mundial de la Paz (2004), Un compromiso siempre actual: educar a la paz, $\mathrm{n}^{\circ} 4$.

${ }^{52}$ Ibid., $\mathrm{n}^{\mathrm{o}} 5$.

${ }^{53}$ Ver el Ángelus del 16 de marzo de 2003, n 2.

${ }^{54}$ Ver el Mensaje de Juan Pablo II para la XXXVII Jornada Mundial de la Paz (2004), Un compromiso siempre actual: educar a la paz, $\mathrm{n}^{\mathrm{o}} 10$.
} 
espíritu idealista ${ }^{55}$, esperanzador, propio, en teoría, de la juventud: "que ellos, con su entusiasmo y su impulso hacia los ideales, pueden ofrecer al mundo una nueva esperanza"56. Las palabras "ideales" y "esperanza" están esparcidas por todo el discurso, de manera que le dan a este un tono optimista, lo que, en medio de una situación de crisis - "una crisis cuyas raíces son sobre todo culturales y antropológicas" $" 57$ - podría ser entendido como temeridad, pero que en este caso es, simplemente, un ejercicio de cordura y realismo: son los jóvenes, educados en el respeto a la dignidad humana, la verdad, la libertad y la paz quienes sentarán las bases de "una sociedad con un rostro más humano y solidario" "58. Así viene enunciado en el primer apartado de su discurso:

Parece como si un manto de oscuridad hubiera descendido sobre nuestro tiempo y no dejara ver con claridad la luz del día. En esta oscuridad, sin embargo, el corazón del hombre no cesa de esperar la aurora de la que habla el salmista. Se percibe de manera especialmente viva y visible en los jóvenes, y por esa razón me dirijo a ellos teniendo en cuenta la aportación que pueden y deben ofrecer a la sociedad. $^{59}$

No obstante, en su Mensaje, el papa no deja de tratar aquellos temas centrales en su pensamiento y que aparecen de una u otra manera en todos sus documentos: la dignidad de la persona humana, una recta concepción antropológica, la denuncia del relativismo, la afirmación del valor de la ley moral natural como fundamento de una justicia universal, el desarrollo humano integral, el conocimiento de la verdad como vía para disfrutar de una auténtica libertad, y el papel de distintos agentes sociales (familia ${ }^{60}$, administraciones públicas y medios de comunicación ${ }^{61}$ ) en la búsqueda del bien común. Además, algo que reitera el pontífice en sus mensajes para estas jornadas es la idea de que la paz es a la vez un don de Dios y una tarea de los hombres, que en esta ocasión se expresa del siguiente modo: "[La paz] es ante todo don de Dios. [...] Pero la paz no es sólo un don que se recibe, sino también una obra que se ha de construir. [...] La paz no es un bien ya logrado, sino una meta a la que todos debemos aspirar" ${ }^{\prime 62}$. Además, ofrece un resumen de algunas de las tareas que tienen por delante los "constructores de la paz":

\footnotetext{
55 "La fe no se opone a vuestros ideales más altos, al contrario, los exalta y perfecciona". Ver la Homilía del Santo Padre Benedicto XVI durante la vigilia de oración con los jóvenes en el Aeropuerto Cuatro Vientos de Madrid, celebrada el sábado 20 de agosto de 2011.

${ }^{56}$ Ver Mensaje para la XLV Jornada Mundial de la Paz (2012), no 1.

57 Ibid.

58 Ibid.

${ }^{59}$ Ibid.

60 "La familia es ciertamente el lugar propicio para aprender y practicar la cultura del perdón, de la paz y la reconciliación". Ver la Exhortación apostólica postsinodal, Africae munus, sobre la Iglesia en África al servicio de la reconciliación, la justicia y la paz, n 43. Hay que tener en cuenta también que "Ellos [los niños] aprenden a amar en cuanto son amados gratuitamente, aprenden el respeto a las otras personas en cuanto son respetados, aprenden a conocer el rostro de Dios en cuanto reciben su primera revelación de un padre y una madre llenos de atenciones. Cuando faltan estas experiencias fundamentales, es el conjunto de la sociedad el que sufre violencia y se vuelve, a su vez, generador de múltiples violencias". Ver la Carta de la Congregación para la Doctrina de la Fe a los obispos de la iglesia católica sobre la colaboración del hombre y la mujer en la Iglesia y el mundo, 31 de mayo de 2004, 13 d).

61 "Todos sabemos que las nuevas tecnologías de la información pueden llegar a ser potentes instrumentos de cohesión y de paz o, por el contrario, promotores eficaces de destrucción y división. Pueden ayudar o perjudicar en el plano moral, propagar tanto lo verdadero como lo falso, proponer lo bello o lo indecoroso". Ibid., n 143. Ver también el $n^{\circ} 144$.

${ }^{62}$ Ver Mensaje para la XLV Jornada Mundial de la Paz (2012), nn. 5 y 6.
} 
Para ser verdaderamente constructores de la paz, debemos ser educados en la compasión, la solidaridad, la colaboración, la fraternidad; hemos de ser activos dentro de las comunidades y atentos a despertar las consciencias sobre las cuestiones nacionales e internacionales, así como sobre la importancia de buscar modos adecuados de redistribución de la riqueza, de promoción del crecimiento, de la cooperación al desarrollo y de la resolución de los conflictos. ${ }^{63}$

Retomando el discurso a los jóvenes profesores universitarios pronunciado en la Basílica de San Lorenzo en El Escorial el agosto pasado -señala en el segundo apartado del Mensaje- "La educación es la aventura más fascinante y difícil de la vida" 64 y que "se nutre del encuentro de dos libertades, la del adulto y la del joven". Afirma, además que "los testigos auténticos, y no simples dispensadores de reglas o informaciones, son más necesarios que nunca". Hace así un llamamiento a los educadores para que sean auténticos testigos de la verdad; no sólo de los conocimientos o de las habilidades profesionales sino, especialmente, de la verdad del ser humano, de la naturaleza humana, porque sólo a través de ese conocimiento se puede construir una sociedad justa y en paz:

En este sentido, los jóvenes necesitan auténticos maestros; personas abiertas a la verdad total en las diferentes ramas del saber, sabiendo escuchar y viviendo en su propio interior ese diálogo interdisciplinar; personas convencidas, sobre todo, de la capacidad humana de avanzar en el camino hacia la verdad. ${ }^{65}$

En ese mismo discurso - después de citar la invitación que hizo Platón a buscar la verdad mientras se es joven ${ }^{66}$ - recalca la idea de que la educación no es mera transmisión de datos: "Esta alta aspiración es la más valiosa que podéis transmitir personal y vitalmente a vuestros estudiantes, y no simplemente unas técnicas instrumentales y anónimas, o unos datos fríos, usados sólo funcionalmente". ${ }^{67}$

Por ello, la educación — prosigue su Mensaje en su tercer apartado — ha de ir vinculada a la búsqueda de la verdad y de la libertad, que es uno de los anhelos más profundos del ser humano, como expresó san Agustín: "Porque, ¿qué ama el alma con más fuerza que la verdad?"68. De ahí que el papa exprese su preocupación: "para educar en la verdad es necesario saber sobre todo quién es la persona humana, conocer su naturaleza"69.

Dado que aquí es donde reside la clave para llegar a la paz a través de la educación: la educación de la libertad humana. El papa entiende que ésta - la libertad- es un don precioso pero que puede ser mal empleado si se queda desligada del conocimiento del bien y del mal, de lo adecuado al ser humano, de la idea recta de justicia, en definitiva de la ley moral natural:

En lo más íntimo de la conciencia el hombre descubre una ley que él no se da a sí mismo, sino a la que debe obedecer y cuya voz lo llama a amar, a hacer el bien y

\footnotetext{
${ }^{63}$ Ver Mensaje para la XLV Jornada Mundial de la Paz (2012), $\mathrm{n}^{\mathrm{o}} 5$.

${ }^{64}$ Ver Mensaje para la XLV Jornada Mundial de la Paz (2012), n ${ }^{\circ} 2$.

${ }^{65}$ Ver el Discurso de Benedicto XVI en el encuentro con los jóvenes profesores universitarios pronunciado en la Basílica de San Lorenzo de El Escorial el viernes 19 de agosto de 2011.

66 "Busca la verdad mientras eres joven, pues si no lo haces, después se te escapará de entre las manos". Ver Parménides, $135 \mathrm{~d}$.

${ }^{67}$ Ver el Discurso de Benedicto XVI en el encuentro con los jóvenes profesores universitarios pronunciado en la Basílica de San Lorenzo de El Escorial el viernes 19 de agosto de 2011.

${ }^{68}$ Ver su Comentario al Evangelio de S. Juan, 26,5.

${ }^{69}$ Ver Mensaje para la XLV Jornada Mundial de la Paz (2012), no 3.
} 
huir del mal, a asumir la responsabilidad del bien que ha hecho y del mal que ha cometido. $^{70}$

Sin embargo, el vínculo entre naturaleza humana, Ley Natural y derechos humanos ya ha sido expresada por el Romano Pontífice en diversas ocasiones ${ }^{71}$, entre la que destaca su discurso ante la Asamblea General ONU en abril de 2008:

Estos derechos se basan en la Ley Natural inscrita en el corazón del hombre y presente en las diferentes culturas y civilizaciones. Arrancar los Derechos Humanos de este contexto significaría restringir su ámbito y ceder a una concepción relativista, según la cual el sentido y la interpretación de los derechos podrían variar, negando su universalidad en nombre de los diferentes contextos culturales, políticos, sociales e incluso religiosos. ${ }^{72}$

En el presente mensaje de enero de 2012 lo afirma de una manera muy sencilla: "La ley natural sienta la base de los derechos y deberes fundamentales, y, por tanto, en último análisis,

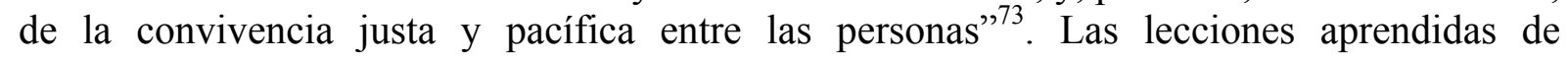
prácticamente todas las misiones de paz realizadas por organizaciones internacionales vienen a sugerir las dificultades experimentadas sobre el terreno para evitar que rebrote la violencia, es decir, la necesidad de construir una paz verdadera y duradera, no falsa, aparente o frágil, como apunta el Santo Padre en el siguiente párrafo:

El uso recto de la libertad es, pues, central en la promoción de la justicia y la paz, que requieren el respeto hacia uno mismo y hacia el otro, aunque se distancie de la propia forma de ser y vivir. De esa actitud brotan los elementos sin los cuales la paz y la justicia se quedan en palabras sin contenido: la confianza recíproca, la capacidad de entablar un diálogo constructivo, la posibilidad del perdón, que tantas veces se quisiera obtener pero que cuesta conceder, la caridad recíproca, la compasión hacia los más débiles, así como la disponibilidad para el sacrificio. ${ }^{74}$

Parece, también, que el papa reconoce, en el $n^{\circ} 3$, que sin reconciliación, sin perdón, no será posible la paz. Este tema fue recurrente durante el año 2011, en el que se celebró el sínodo africano, fruto del cual el papa publicó la Exhortación apostólica postsinodal, Africae munus, sobre la Iglesia en África al servicio de la reconciliación, la justicia y la paz. Ya en 2009 el papa se dirigió a la curia romana con las siguientes palabras sobre la reconciliación:

Se podría decir que reconciliación y justicia son las dos condiciones esenciales de la paz que, por consiguiente, también definen en cierta medida su naturaleza. [...] Reconciliación es un concepto pre-político y una realidad pre-política, que precisamente por eso es de suma importancia para la tarea de la política misma. Si

\footnotetext{
${ }^{70}$ Ver la Constitución Pastoral del Concilio Ecuménico Vaticano II, Gaudium et spes, 16.

${ }^{71}$ Ver Alonso, Antonio y Corral, Carlos: "Benedicto XVI ante la ONU, 18 de abril de 2008", UNISCI

Discussion Papers, $\mathrm{n}^{\circ} 17$ (Mayo de 2008), en

http://www.ucm.es/BUCM/revistas/cps/16962206/articulos/UNIS0808230227A.PDF.

${ }^{72}$ Ver el Discurso de Benedicto XVI ante la Asamblea General de las Naciones Unidas, Nueva York, 18 de abril de 2008, en http://www.vatican.va.

${ }^{73}$ Ver Mensaje para la XLV Jornada Mundial de la Paz (2012), nº 3.

${ }^{74}$ Ibid.
} 
no se crea en los corazones la fuerza de la reconciliación, el compromiso político por la paz se queda sin su presupuesto interior. ${ }^{75}$

Y en 2011, el papa, como no podía ser de otra manera, ofreció el signo de la cruz como signo pedagógico de la reconciliación y el perdón justo un día antes de la Jornada de reflexión y oración por la paz celebrado en Asís: "La cruz es el nuevo arco de paz, signo e instrumento de reconciliación, de perdón, de comprensión; signo de que el amor es más fuerte que todo tipo de violencia y opresión, más fuerte que la muerte: el mal se vence con el bien, con el amor". ${ }^{76}$

Precisamente fue en Asís donde afirmó, delante de representantes de otras religiones y confesiones religiosas (incluidos agnósticos y ateos) que "Puesto que la violencia llega a hacerse normal, se destruye la paz y, en esta falta de paz, el hombre se destruye a sí mismo"77. Se hace, pues, necesaria la tarea de una educación de la juventud que devuelva su sentido a la libertad y permita construir un mundo no dominado por el poder o el poseer: "La adoración de Mamón, del tener y del poder, se revela una anti-religión, en la cual ya no cuenta el hombre, sino únicamente el beneficio personal" ${ }^{17}$.

Volviendo al tema de la reconciliación, Benedicto XVI recuerda en la Africae munus que "sólo una auténtica reconciliación engendra una paz duradera en la sociedad" y que esto es tarea no sólo de los gobernantes sino también de la base social, de manera que "Dando y acogiendo el perdón se ha podido sanar la memoria herida de personas o de comunidades, $\mathrm{y}$ familias antes divididas hayan encontrado la armonía". Pero el papa advierte que

Para llegar a ser efectiva, esta reconciliación deberá ir acompañada de un gesto valiente y honrado: buscar a los responsables de esos conflictos, de los que han ordenado los crímenes y se han entregado a toda clase de componendas, determinando su responsabilidad. Las víctimas tienen derecho a la verdad y a la justicia. Es importante actualmente y para el futuro purificar la memoria para construir una sociedad mejor en la que estas tragedias no se vuelvan a repetir. ${ }^{79}$

Benedicto XVI tocó la cuestión del derecho a la educación de los niños en su encíclica Caritas in veritate, como parte integrante del desarrollo completo del ser humano:

Una solidaridad más amplia a nivel internacional se manifiesta ante todo en seguir promoviendo, también en condiciones de crisis económica, un mayor acceso a la educación que, por otro lado, es una condición esencial para la eficacia de la cooperación internacional misma. Con el término "educación" no nos referimos sólo a la instrucción o a la formación para el trabajo, que son dos causas importantes para el desarrollo, sino a la formación completa de la persona. ${ }^{80}$

\footnotetext{
${ }^{75}$ Ver Benedicto XVI, discurso a la curia romana para el intercambio de felicitaciones con ocasión de la Navidad, lunes 21 de diciembre de 2009.

${ }^{76}$ Ver Benedicto XVI, Audiencia General, miércoles 26 de octubre de 2011.

${ }^{77}$ Ver Jornada de reflexión, diálogo y oración por la paz y la justicia en el mundo, "Peregrinos de la verdad, peregrinos de la paz", Intervención del Santo Padre Benedicto XVI, en Asís, Basílica de Santa María de los Ángeles, Jueves 27 de octubre de 2011.

${ }^{78}$ Ibidem.

${ }^{79}$ Ver la Exhortación apostólica postsinodal, Africae munus, sobre la Iglesia en África al servicio de la reconciliación, la justicia y la paz, $\mathrm{n}^{\mathrm{o}} 21$.

${ }^{80}$ Ver Benedicto XVI, encíclica Caritas in veritate, sobre el desarrollo humano integral en la caridad y en la verdad, 29 de junio de $2009, \mathrm{n}^{\circ} 61$.
} 
En dicha encíclica, Benedicto XVI hace el mismo llamamiento que hiciera Juan Pablo II de fijarse en el ejemplo de las personas que promueven la paz: "Todo esto debe estar unido al esfuerzo anónimo de tantas personas que trabajan decididamente para fomentar el encuentro entre los pueblos y favorecer la promoción del desarrollo partiendo del amor y de la comprensión recíproca" $"$.

Por último, su Mensaje al Cuerpo Diplomático de este año también recoge este tema de la educación para la paz ${ }^{82}$.

\subsection{Lecciones aprendidas de la ONU v de la OSCE}

La ONU es una organización muy compleja de cuyo seno han nacido otras organizaciones o programas que también tienen entre sus objetivos educar a la infancia y a los jóvenes en la paz, como son la UNESCO y el PNUD. Además, tanto ONU como OSCE tienen una dilatada experiencia en misiones de paz, entendidas de manera amplia, y ambas han señalado la importancia del papel de la educación como elemento calve para borrar las huellas de enfrentamientos pasados y para enseñar a las nuevas generaciones a aceptar a los que son diferentes y a convivir con ellos de manera pacífica.

Si se atiende al marco normativo internacional, el derecho a la educación se encuentra encuadrado en los derechos económicos, sociales y culturales y está presente en la Declaración Universal de los Derechos Humanos (1948) en su art. 26, en el art. 7 de la Declaración de los Derechos del Niño (1959), en el art. 18.4 del Pacto Internacional de Derechos Civiles y Políticos (1966), en los art. 13 y 14 del Pacto Internacional de Derechos Económicos, Sociales y Culturales (1966) y en el art. 2 Protocolo Adicional al Convenio para la Protección de los Derechos Humanos y de las Libertades Fundamentales del Consejo de Europa (1952). En todos ellos aparecen, expresados de una u otra manera, tres elementos esenciales. En primer lugar, se manifiesta el derecho y la obligación de los niños a acceder a la educación básica de manera que todos los niños puedan llegar en pie de igualdad a los niveles superiores de la educación. En segundo lugar, que el contenido de dicha instrucción sea coherente con los derechos humanos, fomente el respeto a los demás, rechace la discriminación por cualquier motivo y favorezca la paz. Por último, el derecho de los padres de dar una educación a sus hijos conforme a sus convicciones filosóficas o religiosas.

El art. 7 de la Declaración de los Derechos del Niño hace hincapié, además, en su literalidad en la conciencia de que se están formando a los futuros ciudadanos de pleno derecho del país del que se trate, lo que conlleva que se eduque a las nuevas generaciones en la responsabilidad y el compromiso con la propia sociedad: "Se le dará una educación que favorezca su cultura general y le permita, en condiciones de igualdad de oportunidades, desarrollar sus aptitudes y su juicio individual, su sentido de responsabilidad moral y social y llegar a ser un miembro útil de la sociedad". Esa llamada a la responsabilidad y a la participación activa del gobernado entronca directamente con el torrente de enseñanza que emana desde la Santa Sede sobre materia social, y que brevemente se ha expuesto con anterioridad.

La Conferencia auspiciada por la ONU, reunida en Madrid del 23 al 25 de noviembre de 2001 con ocasión del vigésimo aniversario de la Declaración sobre la Eliminación de Todas las Formas de Intolerancia y de Discriminación fundadas en la Religión o las Convicciones, adoptada el 25 de noviembre de 1981 por la Asamblea General de las Naciones Unidas,

\footnotetext{
${ }^{81}$ Ibid., $\mathrm{n}^{\mathrm{o}} 72$.

${ }^{82}$ Ver Corral, Carlos: "Panorámica del mundo 2011 por Benedicto XVI (9-1-12)", Blog de Carlos Corral, $\mathrm{n}^{\circ}$ 268, en http://blogs.periodistadigital.com/carloscorral.php.
} 
Subrayó "la urgente necesidad de fomentar, mediante la educación, la protección y el respeto a la libertad de religión o de convicciones para fortalecer la paz, el entendimiento y la tolerancia entre individuos, grupos y naciones, y para el desarrollo del pluralismo;, ${ }^{, 83}$.

El Consejo de Derechos Humanos (sucesora de la Comisión de Derechos Humanos) de la ONU remarca continuamente la importancia de una educación en valores que fomente la tolerancia y prevenga el odio desde edades tempranas. Así, cada año aprueba una Resolución sobre la Eliminación de todas las formas de intolerancia religiosa. El 24 de marzo de 2011 el Consejo de Derechos Humanos aprobó la Resolución aprobada por el Consejo de Derechos Humanos 16/18: Lucha contra la intolerancia, los estereotipos negativos y estigmatización, la discriminación, la incitación a la violencia y la violencia contra las personas basada en la religión o las creencias y la Asamblea General la aprobó por la Resolución A/HRC/RES/16/18 de 12 de abril. En dicha Resolución, el Consejo de Derechos Humanos

se suma a su [del Secretario General ONU] llamamiento a los Estados para que tomen las siguientes medidas a fin de promover un entorno nacional de tolerancia religiosa, paz y respeto: g) Comprender la necesidad de combatir la difamación y los estereotipos religiosos negativos de personas, así como la incitación al odio religioso, formulando estrategias y armonizando medidas a nivel local, nacional, regional e internacional, en particular mediante actividades de educación y concienciación;

Todavía dentro del marco de la ONU, el PNUD ha desarrollado toda una doctrina en torno a la importancia de la educación para fomentar el desarrollo de los países y la estabilidad global. A través de su Informe sobre Desarrollo Humano, el PNUD ha ido fomentando año tras año la conciencia de que garantizar niveles adecuados de educación a los jóvenes es una apuesta segura por el desarrollo de un país y por la estabilización de la región en la que se inserta. Aunque el índice de desarrollo humano se centra en tres aspectos principalmente (poder adquisitivo, atención sanitaria y educación), el PNUD ha centrado cada año su atención en un tema concreto (migraciones, cambio climático, papel de la mujer,...) que interviene de manera directa en el desarrollo, ofreciendo así una panorámica más amplia de lo que es la estabilidad y la seguridad de una región. Tal y como se afirmaba en el Informe de Desarrollo Humano de 2003: "La educación influye en todos los resultados de desarrollo humano" 84 .

En el informe de 1990 explica bien qué concepto tienen de "desarrollo" y qué puede aportar los indicadores principales que utilizan para medir ese desarrollo humano:

El desarrollo humano es un proceso mediante el cual se ofrece a las personas mayores oportunidades. Entre éstas, las más importantes son una vida prolongada y saludable, educaci6n y acceso a los recursos necesarios para tener un nivel de vida decente. Otras oportunidades incluyen la libertad política, la garantía de los derechos humanos y el respeto a sí mismo. El desarrollo le permite a los individuos hacer uso de estas opciones. Nadie puede garantizar la felicidad humana y las alternativas individuales son algo muy personal. Sin embargo, el proceso de desarrollo debe por lo menos crear un ambiente propicio para que las personas, tanto individual como colectivamente, puedan desarrollar todos sus

\footnotetext{
${ }^{83}$ Ver el Documento final de la Conferencia internacional consultiva sobre educación escolar en relación con la libertad de religión o creencias, tolerancia y no discriminación, $\mathrm{n}^{\mathrm{o}} 1$.

${ }^{84}$ Ver el Informe sobre desarrollo humano 2003, Objetivos de Desarrollo del Milenio: Un pacto entre las naciones para eliminar la pobreza, p. 85.
} 
potenciales y contar con una oportunidad razonable de llevar una vida productiva y creativa conforme a sus necesidades e intereses. ${ }^{85}$

En lo que respecta específicamente al componente de la educación dentro de ese índice de desarrollo humano, el informe de 1990 afirma que:

\begin{abstract}
los conocimientos, las cifras sobre alfabetismo son solo un crudo reflejo del acceso a la educación, particularmente a la educación de buena calidad, tan necesaria para llevar una vida productiva en la sociedad moderna. Pero aprender a leer y escribir es el primer paso de una persona hacia el aprendizaje y la adquisición de conocimientos; de manera que las cifras sobre alfabetismo son esenciales en cualquier medición del desarrollo humano. En un conjunto más variado de indicadores, también debe darse importancia a los beneficios de los niveles más altos de educación. Sin embargo, para el desarrollo humano básico, el alfabetismo merece el mayor énfasis. ${ }^{86}$
\end{abstract}

En sus informes de desarrollo humano, el PNUD ha medido los avances en el campo de la educación a través de varios indicadores: la tasa de alfabetización de adultos, el porcentaje de población con al menos educación secundaria completa, la tasa de matriculación en educación primaria, la de secundaria, y la de la terciaria, la tasa de deserción en cualquiera de los niveles, la tasa de repetición en cualquiera de esos niveles, la relación maestro-alumno y el porcentaje de maestros capacitados en educación primaria.

Aquel año 2003, el PNUD se encargó de revisar el cumplimiento de los Objetivos de Desarrollo del Milenio (ODM), cuyo segundo apartado está dedicado a la educación: "Objetivo 2: Lograr la educación primaria universal" y establecía como "Meta 3: Velar por que, para el año 2015, los niños y las niñas de todo el mundo puedan terminar un ciclo completo de educación primaria» ${ }^{, 87}$.

El PNUD pone, además, en relación la calidad de la enseñanza recibida con la búsqueda por parte de esas mismas personas de buscar gobiernos democráticos para sus países: "En el largo plazo, las personas que han obtenido mayor nivel de educación y que han visto mejoras en sus condiciones de vida van perdiendo la disposición a tolerar gobiernos autocráticos" ${ }^{88}$. El informe de 2011 señaló, además que

Como destaca el Informe de 2010, la ampliación de la educación primaria es uno de los grandes triunfos de los últimos 40 años. La cantidad de niños que hoy asisten a la escuela aumentó de $57 \%$ a $85 \%$, y en muchos lugares del mundo la matrícula es casi universal. Sin embargo, persisten algunas brechas. Casi tres de cada 10 niños en edad escolar primaria de países con IDH bajo no están matriculados. Y sigue habiendo una serie de otras limitaciones, algunas de ellas relacionadas con factores ambientales. ${ }^{89}$

\footnotetext{
${ }^{85}$ Ver Human Development Report 1990, p. 19, en http://hdr.undp.org/en/media/hdr_1990_es_indice.pdf.

${ }^{86}$ Ibid., p. 36.

${ }^{87}$ Ver la Resolución aprobada por la Asamblea General ONU 55/2: Declaración del Milenio, no 19. Ver también Informe Sobre Desarrollo Humano 2003: Los Objetivos de Desarrollo del Milenio: un pacto entre las naciones para eliminar la pobreza, pp. 92-97. Por último, ver Objetivos de Desarrollo del Milenio: Informe de 2011, pp. 16-19, en http://www.un.org/spanish/millenniumgoals/pdf/MDG_Report 2011_SP.

${ }^{88}$ Ver el Informe sobre Desarrollo Humano 2011: Sostenibilidad y equidad: Un mejor futuro para todos, p. 26.

${ }^{89}$ Ibid., p. 59.
} 
La UNESCO también ha jugado un papel importante en el desarrollo de una conciencia común sobre la necesidad de la educación como enseñanza de aptitudes y habilidades pero también como formadora de actitudes, especialmente del aprecio por la paz. Desde su Constitución (1945), se afirma que "puesto que las guerras nacen en la mente de los hombres, es en la mente de los hombres donde deben erigirse los baluartes de la paz;", y también

Que la amplia difusión de la cultura y la educación de la humanidad para la justicia, la libertad y la paz son indispensables a la dignidad del hombre y constituyen un deber sagrado que todas las naciones han de cumplir con un espíritu de responsabilidad y de ayuda mutua;

Que una paz fundada exclusivamente en acuerdos políticos y económicos entre gobiernos no podría obtener el apoyo unánime, sincero y perdurable de los pueblos, y que, por consiguiente, esa paz debe basarse en la solidaridad intelectual y moral de la humanidad. ${ }^{90}$

Como se puede apreciar, son ideas ya tratadas anteriormente, en los apartados dedicados a la Doctrina Social de la Iglesia, y enfatizan la necesidad de que la paz sea cosa de todos, no sólo de los gobiernos, y que la paz nace del interior y no es una mera cuestión técnica o económica. En 1974, la UNESCO aprobó una serie de recomendaciones y resoluciones por las que se instaba a los Estados a profundizar en el sentido de una educación para la paz:

La educación debería recalcar que la guerra de expansión, de agresión y de dominación y el empleo de la fuerza y la violencia de represión son inadmisibles y debería inducir a cada persona a comprender y asumir las obligaciones que le incumben para el mantenimiento de la paz. Debería contribuir a la comprensión internacional y al fortalecimiento de la paz mundial, y a las actividades de lucha contra el colonialismo $y$ el neocolonialismo en todas sus formas $y$ manifestaciones, y contra todas las formas y variedades de racismo, fascismo y apartheid, como también de otras ideologías que inspiran el odio nacional o racial y que son contrarias al espíritu de esta Recomendación. ${ }^{91}$

La OSCE también ha puesto especial atención en numerosas ocasiones en la importancia de la educación como instrumento para formar ciudadanos libres de prejuicios de cualquier tipo, para fomentar un espíritu de tolerancia que permita una convivencia pacífica en sociedades multiculturales ${ }^{92}$.

Dentro de la Estrategia de la OSCE frente a las amenazas contra la estabilidad y la seguridad en el siglo XXI adoptada en Maastricht en 2003, se afirma en su no 40 que

\footnotetext{
${ }^{90}$ Ver Constitución de la UNESCO, Londres, 16 de noviembre de 1945.

${ }^{91}$ Recomendación sobre la Educación para la Comprensión, la Cooperación y la Paz Internacionales y la Educación relativa a los Derechos Humanos y las Libertades Fundamentales, aprobada en París el 19 de noviembre de 1974, art. 6. Ver también la resolución Contribución de la Unesco a la paz y funciones de la Unesco en relación con la promoción de los derechos humanos y la liquidación del colonialismo y del racismo, aprobada en París el 22 de noviembre de 1974.

${ }^{92}$ Ver la Guía de principios orientadores de Toledo sobre la enseñanza acerca de religiones y creencias en las escuelas públicas, elaborado por el consejo asesor de expertos sobre libertad de religión o creencia de la ODIHR (OSCE) en 2008.
} 
Los esfuerzos de la OSCE se dirigirán, en particular, a las generaciones más jóvenes a fin de hacerles comprender la necesidad de que haya tolerancia y la importancia de la reconciliación y de la convivencia pacífica. La visión y perspectiva del futuro de dichas generaciones es un factor clave, que debe cuidarse, por lo que la OSCE asumirá, si así procede, una función más activa en la esfera de la educación. Cabe destacar la educación en materia de derechos humanos como merecedora de particular atención. ${ }^{93}$

También en el ámbito de la OSCE encontramos dos Decisiones adoptadas en Sofía en 2004, el Anexo a la Decisión $n^{0} 12 / 04$ sobre tolerancia y no discriminación y la Decisión del Consejo Permanente $n^{\circ}$ 621: la tolerancia y la lucha contra el racismo, la xenofobia y la discriminación, en cuyo $\mathrm{n}^{\circ} 1$ se puede leer que "Los Estados participantes se comprometen a promover y reforzar, cuando proceda, todo programa educativo por el que se fomente la tolerancia y se combata el racismo, la xenofobia y la discriminación;". De semejante tenor es la Decisión $\mathrm{n}^{\circ}$ 10/05: Tolerancia y no discriminación: fomento del entendimiento y del respeto mutuo, adoptada en Liubliana en 2005; la Decisión $n^{\circ}$ 13/06: Lucha contra la intolerancia y la discriminación, y fomento del respeto y el entendimiento mutuos, adoptada en Bruselas en 2006.

La OSCE (continuadora de la CSCE) ha hecho distintos llamamientos a lo largo de sus más de 35 años de existencia a promover la tolerancia y la no discriminación a través de la educación. Si durante bastante tiempo se puso el acento en evitar el antisemitismo, le sucedió en importancia la lucha contra la islamofobia y, poco después, la alerta por el odio contra los cristianos y otras minorías étnicas y religiosas (especialmente los gitanos).

En 2010 se celebró en Astaná a finales de junio, durante la presidencia kazaja rotatoria de la OSCE, una Conferencia de alto Nivel sobre la Tolerancia y la No Discriminación, siendo uno de los bloques tratados el papel de la educación en dicho campo. Esta Conferencia, inaugurada por el presidente kazajo Nursultán Nazarbayev, señaló la importancia de la educación para prevenir comportamientos intolerantes de carácter violento ${ }^{94}$. La OSCE 1lama hasta en tres ocasiones (puntos 1, 2 y 11) en la denominada Declaración de Astaná a utilizar la educación como instrumento para evitar los odios basados en la intolerancia y la incomprensión ${ }^{95}$.

Por otro lado, los defensores de los estudios sobre la paz han defendido siempre la idea de que la educación de las nuevas generaciones es un factor fundamental para el fortalecimiento de la sociedad y para garantizar unas estructuras sociales más justas y democráticas. Entre estos autores encontramos, entre otros, a Johan Galtung y a H. B. Danesh $^{96}$.

\footnotetext{
${ }^{93}$ Ver la Estrategia de la OSCE frente a las amenazas contra la estabilidad y la seguridad en el siglo XXI, adoptada en 2003 en la Undécima Reunión del Consejo Ministerial de Maastricht, en http://www.osce.org. ${ }^{94}$ Del mismo tenor es la siguiente afirmación de Benedicto XVI en Africae munus, no 94: "Si todos nosotros, creyentes en Dios, deseamos servir a la reconciliación, la justicia y la paz, hemos de trabajar juntos para impedir toda forma de discriminación, intolerancia y fundamentalismo confesional".

${ }^{95}$ Ver un resumen de las intervenciones en Summary report of the OSCE high-level conference on tolerance and non-discrimination 28-30 June 2010, Astana, Kazajstán, CIO.GAL/168/10

(29 de septiembre de 2010), pp. 19-21, en http://www.osce.org/cio/71469.

${ }^{96}$ Entre sus obras más destacadas tenemos Galtung, Johan (1975): Essays in Peace Research, Volume 1. Copenhagen, Eljers. pp. 334-339; también Danesh, H. B.: "Towards an integrative theory of peace education", Journal of Peace Education, vol. 3, $\mathrm{n}^{\circ} 1$ (2006), pp. 55-78. Otras obras de distintos autores sobre la educación
} 


\section{Conclusiones}

Como se ha podido observar a lo largo del artículo, la educación para la paz es uno de los elementos que forman este complejo mosaico de la seguridad. Tanto la Doctrina Social de la Iglesia como numerosos autores a lo largo de los siglos han puesto de manifiesto que la guerra, como manifestación extrema y última de la violencia organizada, es también fruto de una mentalidad difundida entre los habitantes de un territorio dado y no sólo un impulso ciego e inexorable de la naturaleza humana.

No obstante, para que la paz arraigue en esta tierra, debe existir también una firme voluntad en los gobernantes, que son quienes al final toman las decisiones en cuestiones de seguridad, de evitar por todos los medios el recurso a la guerra y apostar continuamente por la paz.

Formar las conciencias de las jóvenes generaciones en el sentido del respeto absoluto a la vida y a la dignidad de las personas, basándose en el derecho natural, es garantía de un futro en paz.

para la paz son: Harris, I.M.: “Types of peace education”, en Raviv, A.; Oppenheimer, L. y Bar-Tal, D. (eds.) (1999): How Children Understand War and Peace, San Francisco, Jossey- Bass, pp. 299-31; Johnson, M.L.: "Trends in peace education", ERIC Digest, no 417123 (Febrero 1998); Kreidler, William J. (1990): Elementary Perspectives 1: Teaching Concepts of Peace And Conflict. Cambridge, MA. Educators for Social Responsibility. 